\title{
A CULTURED NEURON PROBE
}

\author{
Jerome Pine, Michael Maher, Steven Potter, Yu-Chong Tai, Svetlana Tatic-Lucic, and John \\ Wright, California Institute of Technology 256-48, Pasadena, California, 91125, USA.
}

\author{
Gyorgy Buzsaki and Anatol Bragin, Rutgers University, \\ 197 University Avenue, Newark, NJ 07102, USA
}

\begin{abstract}
Work in progress toward the creation of a "cultured neuron probe" is described. This is a silicon structure similar to that for a multielectrode probe, but with embedded neurons which are intended to grow out and integrate with the neurons of a host nervous system into which the probe has been inserted. Each probe neuron is in close proximity to an electrode which is designed for extracellular stimation and recording from the probe neuron. In this way the probe neurons may provide a highly specific longterm communication link between external electronics and the host. Initial experiments to establish the feasibility of the concept will be done in rat hippocampus.
\end{abstract}

\section{INTRODUCTION}

In order to create neural prostheses to help people better cope with such disabilities as paralysis, deafness, or blindness, there is a need for long term connections to their nervous system. To date such communication has been established by using metal electrodes, which make non-specific contact to many cells in the neighborhood of the electrode tip. It would be desirable for communication with the central nervous system if there was specificity to a particular cell type. This could provide, for example, for recording control signals from the cortical pyramidal cells which drive spinal cord neurons. For visual stimulation, connections of the geniculo-cortical pathway could be mimicked. In addition, for chronic stimulation, it would be desirable to have neuron specificity to avoid change in effectiveness over time, which is observed with less selective electrical stimulation.

In recent years, researchers in neural transplantation have achieved long term survival of implanted neurons, and have observed cell-specific integration into the host nervous system [1]. Also, in recent years, silicon device microfabrication technology has evolved for the production of complex multielectrode probe structures for chronic implantation into the central nervous system [2]. This project involves a combination of these two developments. Silicon probe structures are being made which can hold captive neurons, in close proximity to an electrode. When the probe is implanted with neurons in it, it is hoped that axons and dendrites from these neurons will grow out and integrate with the host nervous system. The probe electrodes can then be used for two-way connection to the host by using the probe neurons as highly selective intermediaries.

\section{PROJECT DESIGN}

We have chosen the rat hippocampus as a trial target for the cultured neuron probe. Fig. 1 below shows a schematic view of the probe, along with a sketch indicating the placement of the probe in the pyramidal cell layer of the hippocampus of an adult rat.

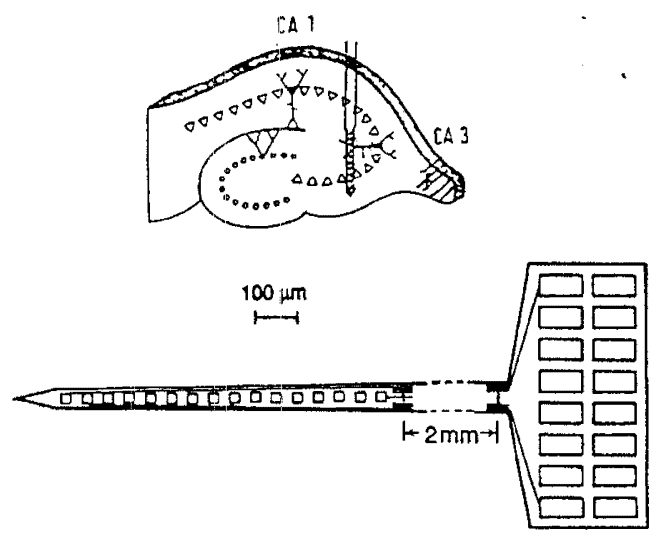

Fig. 1. Probe schematic and placement.

Neurons are dissected from day 18 rat embryos, and placed in the 16 probe wells shown schematically in the sketch. It is known from transplant studies that embryonic neurons are best suited for survival and outgrowth, and that they tend to make connections to what would be their normal targets. It is hoped therefore that probe neurons will integrate with the host hippocampal cells.

A neuron well structure is illustrated in Fig. 2 below. By using an anisotropic EDP (ethylene-diaminepyrocatechol) etch, truncated-pyramid wells can be 
formed under a pattemed slicon dioxide grillwork. Whe contral hole provides entry Mrough which dissociated mewron car be inserted using a micropipete. Arons and dendriles growing out through the comer holes will then trap the neuron. Cledrodes in the bottom of the wells are connected by insulated gold loads to pads at the probe handle from which fowble load can be brought to a skull plug

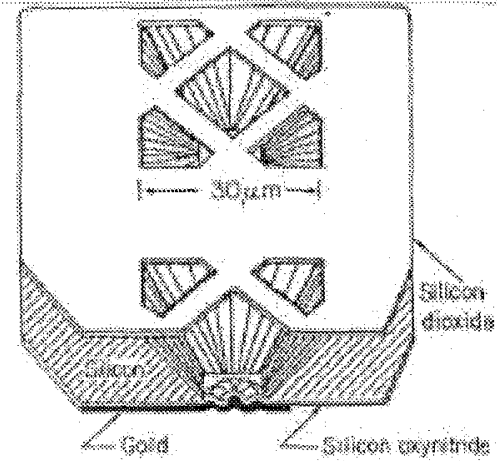

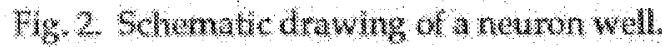

For the projoct to succed, a number of isenes must we add rased:

1. Probes must be fabricated, with procesaing and patteruning on both sides of a 16 micrn thick memulwate:

2.Newrons mast survive and grow out of wall 3 The woway dectrical connection from probe fedrode to weurot must be cfective.

4 Weurme must arvive and grow in the hosk.

5. The existence of probe-host communnication must boestablikhnd.

The group at Calted has worked on in whe studies and fabrication to addres sues 1-3, while the group at Rutgers has addresed wswes 1 and 5 .

\section{MBRCAWON}

A thin membrank is fomed from epewaters whid mcorporate a bur meron thek heavily boron-doped Layer under 16 miscons a lighty doped (100) silicon. Using LDF, $5 \times 9 \mathrm{~mm}$ basin " are etched through the $\$ 00$ micton thek shicon substrate to the boron atch stop, for form thinned regions for probe formation. Using projection lithography, the grillwork is bomed at the bothom of the basin, while electrodes and leads are formed on the opposite side. These comnact 6 bond pads on fulthickess sllicon surounding the basin regiox, formings the probe handle The scanning dectron micrograph below $\mathrm{Fig}, 3$, how whe kp region of a completed probe.

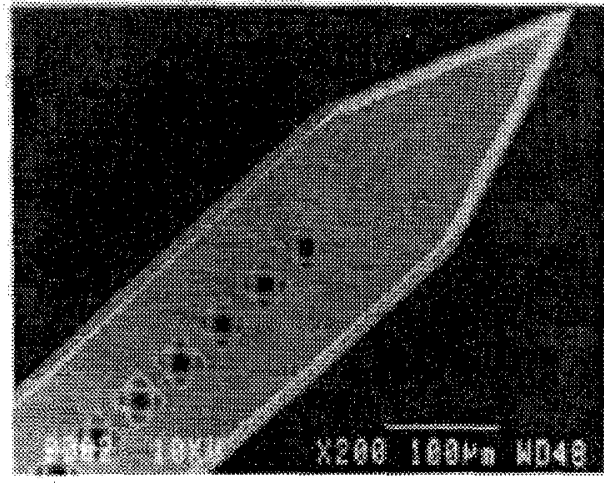

Fig. 3. The tip region of a completed probe:

In order lo foclitate in witro lests, "neutochips are also made, which incorporate a 4 \& arwa of well at the center of he bosin, and have loads to bond pads at the perphery of a $1 \mathrm{~cm}$ square full hickness ow whol encompasses the basin [3].

\section{W. NVTKO SruDLEs}

The well design shown in Fig. 2 was lested succestfully for survival and outgrawth of nat sympathetic netrons. However, when hippotampat pyramidal cells were ased it was found hat trapping o? the netron was unsuccesstul. Alter a shor lime he dendrites were seen lo retrad and he cell body almwer ont of the conner hole along the axon perhe minicking its behavior during devalopment in witw. In

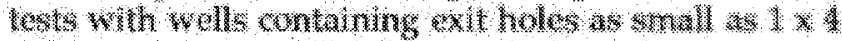
microns, neurons roughly 5 tricrons in dimeter deformed themselves so as to paus through the holw

To successtully trap the hippocampal cels a new well design was made, and succestully fabricaked. In the decign he neuron processes grow out of the wall Hrowgh wumels. This well design is shown al lef in Fig. 4, wewed with Nomarski optics.
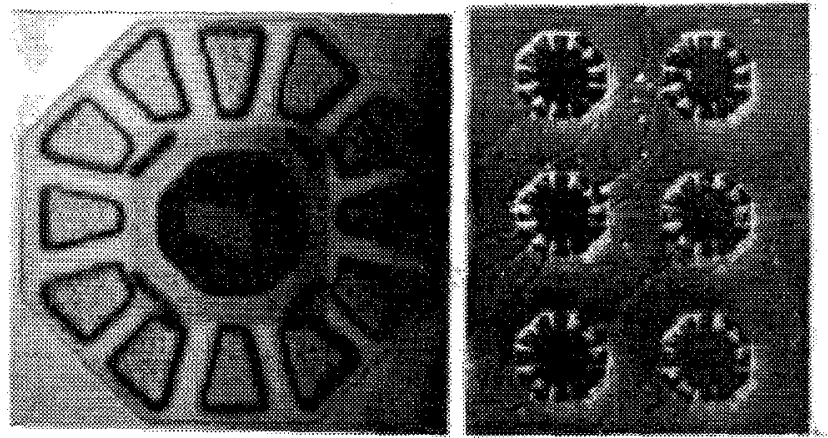

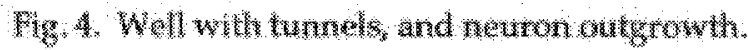


The octagonal shape shows the outline of a 0.5 micron thick silkow nitride canopy. The square gray area at the center defines the lop of the well. $A$ hole in the center of the witride canopy provides for inserting a dissoctated neuron. The four small slots at the comer of this area define the boundaries for the EDP etch which undercuts the nitride to form the well. The 12 dear regions radiating outward from the center are tunnels; 15 microns high, 4 microns wide, and 15 microns long; through which neuron processes grow. The canopy is really not flat, but bends down 0.5 microns to anchor to the silicon substrate at the irregular gray areas between watwels. The anchor regions and tunnes are formed by deposiling nitride on pallerned LPCVD low temperature silicon droxide 0.5 microns thidk, which is removed by ctching with $8 \%$ HF 10 leave the final structure.

At the right in Fig. 4 , part of the area of a neurochip with these wells is shown. Vigorous outgrowth of hippocampal cells through the tunnds is seen for netrons one day in culture:

A second set of in witro studies has been made with "dumny probes" which have wells but not electrodes. in order to study outgrowth into cultured hippocampal slice: It onder 60 observe the probe neurons and their prockss a protocol for staming dissociated neurons with the membrane-bound stain Dil was developed. This staining allows observation of processes growing from the cells over a period of at leakt wo weeks. It wat observed that stained embryonic neurons grow: wigorously into alice from a probe placed on the surtace. If was also discovered that exposing a probe loaded with weurons to dry air for even a few seconds causes cell darmage from dehydration.

\section{NVIVO STUDTES}

Intal studies haw been directed toward determining whether probe neurons survive and grow In host adult rats. These studies have all been performed with dummy probes to look for anatomical evidence of outgrowih. The first method used was: loading the probe with cholinergic septal neurons: These neurons and their processes can be identified after fixation with a dark brown cholinesterase stain. For probe tests, the adull rat was first subjected to lesioning of the septal-hippocampal pathway which provides normal cholinergic inputs. After these cholinergic axons died, the hippocampus, with no cholinergic inputs, was implanted with a probe carrying septal neurons.

The rats were perfused and fixed and the brains sectioned in the vicinity of the probe, after survival
Wimes of one to lurew months. Techniques were established for sectioning in the probe area and parallel to the probe so as to be highly sensitive to outgrowth. In two cases, cholinergic staining was observed from processes which appeared to come from probe neurons: Fig. 5 below shows one example. Stained processes can be seen, growing several hundred microns out of the tip region of a probe.

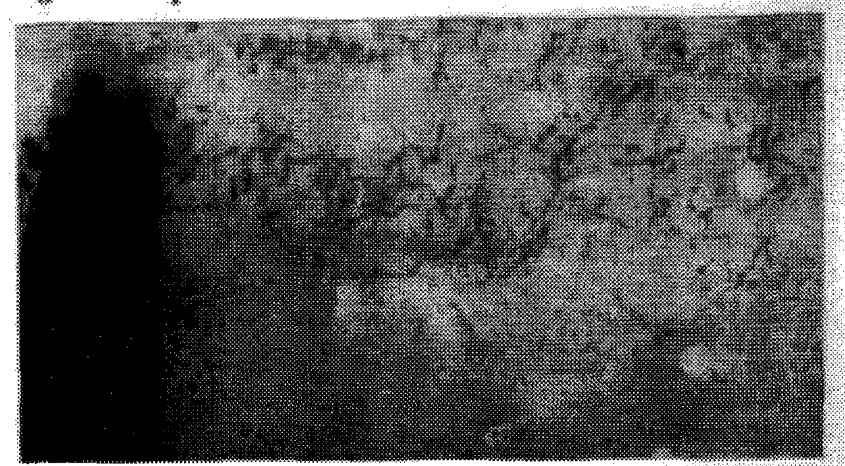

Fig. 5 Stained processes growing out of a probe.

One reason for the low yield of septal outgrowth may have been the well design. Wells used at this time were found to have overhangs which inhibited outgrowth in who Currently, studies are under way with Dil stained hippocampal pyramidal neurons in acute experiments in which probes are inserted and removed after short times. Poor survival, poseibly due to dehydration, and overgrowth by a fibous layer, have been observed. Work is continuing lo first actieve good hort term survival before proceeding with longer term outgrowth experiments.

\section{LEITERNCES}

II) F. H. Gage, Editor, Special iscue on transplantation, Trends in Neuroscience, vol. 14 (8), pp. $319.388,1991$

12. K. Najat and K D Wisc, "An Implantable multielectrode artay with on-dhip signal processing. IETE Joumal on Sold State Circutry, vol 21 , pp. 1035-104, 1986

(3) 5. Tatic-Lucic et al, Silicon-micromachined neurochips for in ottro studics of cultured neural networks," Int I conference on sollu chle sensors and actuators, Yokohama, 1993

This work is supported by the U.S. National Institutes of Fealm, Neural Prosthesis Program 